\title{
Guest editorial: IJAMT special issue on Multi-Material Micro Manufacture
}

\author{
Emmanuel B. Brousseau • Stefan Dimov • \\ Wolfgang Menz
}

Published online: 30 January 2010

(C) Springer-Verlag London Limited 2010

In today's market, miniaturised and microsystems-based products represent key value-adding elements for many industrial sectors and thus, they are an important contributor to a sustainable economy [1]. Following the siliconbased microelectronics revolution of the late twentieth century, a number of micro and nano manufacturing techniques have been developed and implemented into process chains for the fabrication of micro electro mechanical systems (MEMS). Especially, this technology developments target particular niches in the market and as a consequence, a number of MEMS devices are now being effectively exploited commercially.

Interest towards product miniaturisation and in general micro and nano technologies (MNTs) has even increased in recent years given that many companies are realising that MNT-based products provide a competitive advantage and represent innovative and high value-added solutions that will enable them to compete successfully on the global market. Thus, product designers increasingly try to develop new or improved devices that integrate a multitude of functions in order to broaden their application areas without significantly expanding their weight or volume. Such a trend for 'function integration' into new products has recently motivated the R\&D community to investigate and propose novel micro manufacturing techniques and process

\footnotetext{
E. B. Brousseau $\cdot$ S. Dimov $(\varangle) \cdot$ W. Menz

The Manufacturing Engineering Centre, Cardiff University, Queen's Buildings, The Parade Newport Road, Cardiff CF24 3AA, UK

e-mail: dimov@Cardiff.ac.uk

E. B. Brousseau

e-mail: brousseaue@Cardiff.ac.uk

W. Menz

e-mail: menz@imtek.uni-freiburg.de
}

chains, which do not rely only on photolithography-based technologies commonly employed for fabricating MEMS components. In particular, a range of advances in the field of micro and nano manufacturing have been reported, and further developments are necessary to support the production of novel microsystems-based products which require the use of a broad range of materials and incorporate complex three-dimensional structures with high aspect ratios.

According to a recent study which analysed the distribution of European R\&D efforts along a technology maturity scale in the field of MNTs, modest but promising R\&D advances target the integration into production environments of the most important future micro manufacturing technologies [2]. At the same time, this study showed that significant $R \& D$ efforts are still required to address existing challenges at the different phases in developing micro manufacturing technologies. In this context, the focus of this special issue is on the latest scientific advances in manufacturing research to support the development of emerging and potentially disruptive miniaturised devices made in a wide range of materials complementing those commonly used in MEMS devices. The Issue is prepared from selected contributions to the Third Multi-Material Micro Manufacture Conference in Borovets, Bulgaria (4M2007) organised by the 4M Network of Excellence.

The papers in this special issue can be clustered into three main groups. The first group includes papers that are focused on a set of micro manufacturing technologies, which are suitable for the production of micro-structured moulds. In particular, the Issue begins with two papers on micro electro discharge machining (EDM). The first one presents an investigation carried out by Bissacco et al. to characterise the electrode wear and workpiece material 
removal processes when machining micro features in steel. The second paper from Liu et al. describes a study on pulse generation and precision machining carried out on a commercially available micro EDM machine. Next, Popov et al. introduce a new method for setting up the working coordinate system for micro-milling operations in order to reduce machining errors that result from the thermal enlargement of the spindle. Then, the paper by Minev et al. examines the properties of $\mathrm{CrC}$ coatings deposited on tool steel substrates and the response of such coatings to focused ion beam micro and nano structuring, while the contribution from Boy et al. presents research on micro ultrasonic machining. In the subsequent paper, Brechet and Weinzierl propose a new approach for automating an ultraprecision machining process that relies on advanced techniques for tool referencing and workpiece referencing and handling.

The second group of papers in this special issue are concerned with replication techniques underpinning the serial production of micro- and nano-structured components. In particular, Diehl et al. discuss the influence of the material micro structure on the mechanical properties and the forming behaviour of thin metal foils. Next, Piotter et al. describe current trends and developments in the field of multicomponents micro injection moulding that enables serial manufacture of parts made of two different metallic or ceramic materials. The other papers on micro replication focus on techniques for mass production of polymer components. Especially, a new type of reel-to-reel hot embossing machine is investigated by Velten et al. for the high throughput micro patterning of flexible polymer foils. Additionally, the importance of micro injection moulding (MIM) for serial production of micro components is the focus of three other contributions. Tosello et al. propose a novel approach for investigating the significance of different process parameters on the behaviour of the polymer flow front during the MIM filling stage by carrying out an analysis of polymer weld lines. Griffiths et al. present a study in which the effects of different mould coatings in combination with various MIM process parameters are investigated in respect to their influence on the demoulding behaviour of polymer parts with micro features. Another paper by Griffiths et al. demonstrates the feasibility of a new process chain which employs polymer inserts for MIM to reduce the development time and cost of micro fluidic systems prior to their mass fabrication.

Finally, the remaining papers in the special issue address various micro fabrication research topics and are complementary to the other two groups of papers. Ferri et al. investigate a commercial white light interferometer and propose a new technique for calibrating such instruments to enable the accurate dimensional measurements of components with micro features. Nestler et al. examine the application of a set of technologies for micro channel fabrication, treatment and sealing, sensor bonding and lowcost pump integration that are complementary in producing complex polymer micro fluidic systems. Zhu et al. describe an original route for fabricating ceramic micro components by employing a soft moulding technique which relies on low-cost PDMS moulds produced from SU-8 masters. Then, Brechet et al. introduce a novel method for designing efficiently tools for ultrasonic-assisted grinding in order to optimise their dynamic behaviour when manufacturing spherical optics. Finally, a review paper from Brousseau et al. summarises the recent advances in micro and nano manufacturing obtained by the Manufacturing Engineering Centre at Cardiff University in the United Kingdom. In particular, the paper presents research results on a number of master making and replication technologies and discusses future trends in their development.

This special issue has been made possible by the joint efforts of several people. We would like to express our gratitude to Professor John Davies and the members of the Editorial Board of the Journal for encouraging us to prepare this issue, the authors for their contributions, the referees for ensuring the quality of the included papers and the staff at Springer Publishing, in particular Mr. E. Sarmiento and Mr. M. Kraetke for their help in finalising this special issue. We are also grateful to other members of the 4M2007 Programme Committee, especially Professor M. Hristov, Professor D. Dascalu, Professor I. Dragieva, Professor L. Mattsson, Mr. E. Jung, Professor U. Engel, Dr. P. Johander, Dr. C. Wenzel, Dr. M. Richter, Dr. P. Kirby, Dr. A. Schoth and finally, the late Professor Y. Toshev for their advice on various aspects of micro manufacturing technologies and their applications.

\section{References}

1. Dimov SS, Matthews CW, Glanfield A, Dorrington P (2006) A roadmapping study in multi-material micro manufacture. In Proceedings of the Second International Conference on MultiMaterial Micro Manufacture, 4M2006, Grenoble, France, September 20-22, pp xi-xxv

2. Brousseau EB, Barton R, Dimov S, Bigot S (2009) Technology maturity assessment of micro and nano manufacturing processes. In Proceedings of the Fifth International Conference on MultiMaterial Micro Manufacture, 4M2009, Karlsruhe, Germany, September 23-25, pp 257-262 